\title{
Clinical pharmacology of cephalexin administered by intravenous injection
}

\author{
J. A. DAVIES AND J. M. HOLT \\ From the Nuffield Department of Clinical Medicine, The Radcliffe Infirmary, Oxford
}

SYNOPSIS Cephalexin IG was given by intravenous injection to eight normal volunteers, five $\frac{\bar{\Omega}}{\mathrm{O}}$ patients with chronic renal failure, and three patients during a period of haemodialysis. In normali subjects there was a rapid fall in serum concentration and $80 \%$ of the administered dose was excreted $\%$ in the urine within two hours. The mean serum half life was 1.1 hours (range $0.6-1.8$ hours). Prior $G$ treatment with probenecid in two subjects led to a twofold increase in serum concentration two hours $\vec{\infty}$ after injection. In the patients with chronic renal failure antimicrobial activity persisted for 24 hours $ᄋ$ and the half life ranged from $6 \cdot 1$ to $18 \cdot 1$ hours. Haemodialysis led to partial removal of cephalexin ${ }_{c}^{-}$ from the blood, but antimicrobial activity remained eight hours after injection at the end of the dialysis period. The serum half life in these patients was $5 \cdot 1,5 \cdot 6$, and $5 \cdot 7$ hours.

Cephalexin, a semi-synthetic cephalosporin antibiotic, is absorbed effectively from the gastrointestinal tract (Gower and Dash, 1969) and antibacterial activity has been demonstrated against a wide range of Gram-positive and Gram-negative organisms (Wick, 1967). It has recently become available in parenteral form and this study was undertaken to investigate the pharmacokinetics in normal subjects and patients with renal disease.

\section{Materials and Methods}

Cephalexin sodium (Glaxo Laboratories Ltd) was given by intravenous injection to eight healthy adult volunteers (six males and two females), five patients with chronic renal failure, and three patients during a period of haemodialysis using a Kiil dialyser. One gram, dissolved in $5 \mathrm{ml}$ of sterile water, was given slowly over a five-minute period. Blood samples were taken after one quarter, one half, one, two, four, and six or eight hours. A further sample was taken after 24 hours from patients with chronic renal failure. Urine was collected and the volume measured from 0-2, 2-4, and 4-6 hours in normal subjects and from 0-2, 2-4, and 4-8 hours in patients with chronic renal failure. Serum samples and aliquots of each urine collection were stored at $-20^{\circ} \mathrm{C}$ until assay, which was performed within 48 hours of collection. The procedure was repeated in two of the control subjects at a later date following oral administration Received for publication 20 January 1972. of probenecid $500 \mathrm{mg}$ six hourly during the preceding 24-hour period.

Samples were assayed by a modification of the agar-well method using B. subtilis (Bennett, Brodie, Benner, and Kirby, 1966). The serum half life waso calculated from the one to six-hour serum values, $\stackrel{?}{\Rightarrow}$ using the formula: $T \frac{1}{2}=\log 2 / \mathrm{m}$, where $\mathrm{m}$ is theo rate constant of drug elimination obtained by the method of least squares (Kunin and Finland, 1958)

\section{Results}

NORMAL SUBJECTS

Serum concentrations at timed intervals following

\begin{tabular}{|c|c|c|c|c|c|c|}
\hline \multirow[t]{2}{*}{ Subject } & \multicolumn{6}{|c|}{ Serum Concentration $(\mu \mathrm{g} / \mathrm{ml})$} \\
\hline & $\frac{1}{4} \mathrm{Hr}$ & $\mathbf{H r}$ & $1 \mathrm{Hr}$ & $2 \mathrm{Hr}$ & $4 \mathrm{Hr}$ & $6 \mathrm{Hr}$ \\
\hline \multirow{10}{*}{$\begin{array}{l}\text { J.D. } \\
\text { K.H. } \\
\text { J.F. } \\
\text { D.J. } \\
\text { S.P. } \\
\text { M.R. } \\
\text { J.H. } \\
\text { A.D. } \\
\text { J.H. after } \\
\text { probenecid } \\
\text { J.D. after } \\
\text { probenecid }\end{array}$} & 64 & 40 & 17 & 8 & 4 & 2 \\
\hline & 57 & 37 & 18 & 6 & 3 & 2 \\
\hline & 57 & 42 & 23 & 8 & 4 & 0 \\
\hline & 48 & 34 & 18 & 7 & 1 & 0 \\
\hline & 68 & 50 & 24 & 9 & 3 & 1 \\
\hline & 56 & 26 & 10 & 8 & 2 & 0 \\
\hline & 43 & 28 & 10 & 5 & 2 & 0 \\
\hline & 65 & 36 & 20 & 7 & 2 & 0 \\
\hline & 61 & 51 & 32 & 18 & 8 & 3 \\
\hline & 84 & 43 & 26 & 16 & 8 & 4 \\
\hline
\end{tabular}

Table I Serum concentration following intravenous injection of cephalexin IG in eight normal subjects and in two subjects following oral probenecid $500 \mathrm{mg}$ six hourly during the preceding 24 hours 


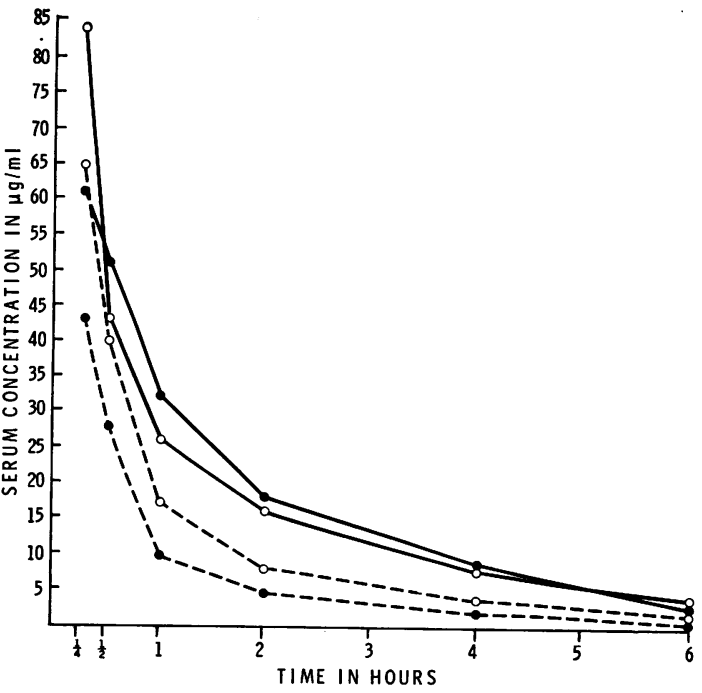

Fig. 1 Effect of probenecid on serum concentration following intravenous administration of cephalexin in two normal subjects; - - - without probenecid,

following oral probenecid $500 \mathrm{mg}$ six hourly during preceding 24 hours.

injection in eight normal subjects are shown in Table I. The mean serum half life was $1 \cdot 1$ hours (range $0.6-1 \cdot 8$ hours, standard deviation \pm 0.7 ). Urinary excretion of the drug during the three collection periods is shown in Table II. Seven of the eight subjects excreted $80 \%$ or more of the administered dose within the first two hours. The effect of probenecid in delaying clearance of cephalexin is shown in Figure 1. After the administration of pro-

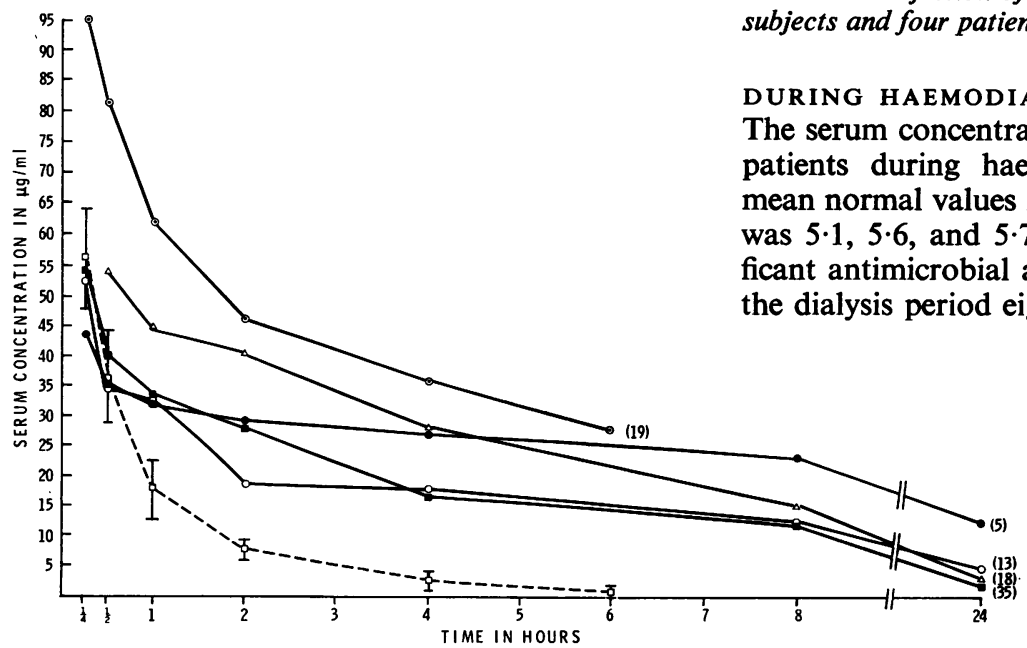

benecid for 24 hours, the serum half life increased from 1.8 and 0.7 to 2.0 and 1.6 hours respectively and the two-hour serum concentration increased twofold (Table I).

\section{CHRONIC RENAL FAILURE}

The serum concentrations at timed intervals for five patients studied are compared with the mean value for normal subjects in Figure 2. The serum half life of the five patients was $6 \cdot 1,6 \cdot 6,8 \cdot 6,11 \cdot 2$, and $18 \cdot 1$ hours respectively. The percentage urinary excretion in four of the five subjects is shown in Table II. In two patients with a creatinine clearance of 5 and $13 \mathrm{ml}$ per minute, less than $20 \%$ of the administered dose was excreted in the first eight hours, whereas approximately $50 \%$ was excreted in the two patients in whom the creatinine clearance was 18 and $19 \mathrm{ml}$ per minute.

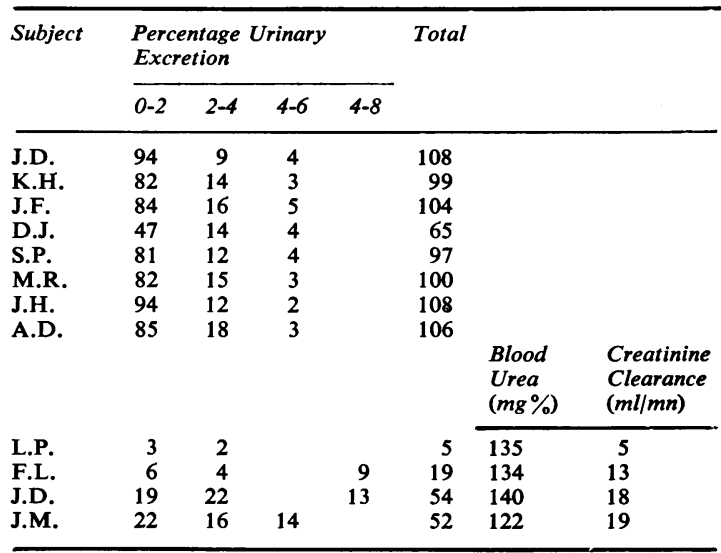

Table II Urinary excretion of cephalexin following intravenous injection of cephalexin in eight normal subjects and four patients with chronic renal failure

DURING HAEMODIALYSIS

The serum concentration at timed intervals in three patients during haemodialysis is compared with in Figure 3. The serum half life hours respectively, and signiactivity remained at the end of

Fig. 2 Serum concentration in five patients with chronic renal failure (-) compared with the mean concentration in eight normal subjects (- - ). Figures in parentheses indicate the creatinine clearance in ml per minute. 


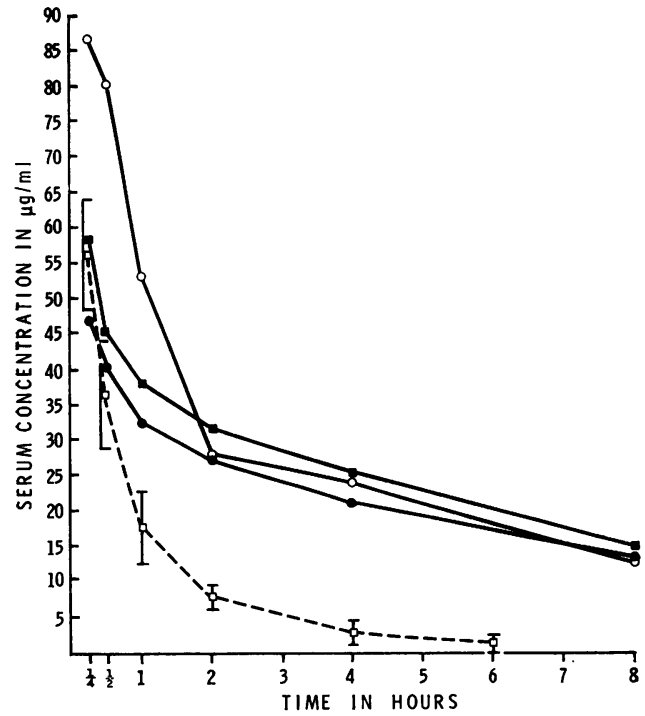

Fig. 3 Serum concentration in three patients during haemodialysis (-) compared with the mean concentration in normal subjects (- - ) following intravenous administration of cephalexin.

\section{Discussion}

These results show that cephalexin administered by intravenous injection is cleared rapidly from the blood and excreted in the urine. The short mean serum half life in normals of $1 \cdot 1$ hours is similar to that reported following oral administration of 1.2 hours (Kabins, Kelner, Walton, and Goldstein, 1970) and 0.9 hours (Kunin and Finkelberg, 1970). A shorter half life of 0.6 hours was reported by de Maine and Kirby (1971), but in their study a steady state was achieved by means of an infusion of $500 \mathrm{mg}$ hourly for three hours beforehand, conditions which differ from those usually applying when a drug is used in clinical practice. A short half life associated with early urinary excretion might limit the clinical usefulness in patients with normal renal function, unless this is compensated for b more frequent injections, administration by intra을 venous infusion, or by the concomitant use of pro $\Rightarrow$ benecid, which delays excretion appreciably (Fig. 19 Gower and Dash (1970) showed also that probeneci政 leads to a striking retention of cephalexin following its administration by mouth.

Significant antimicrobial activity of at lease $12.5 \mu \mathrm{g} / \mathrm{ml}$ persisted for over eight hours in all thछ patients with chronic renal failure studied (Fig. 2) and in the patient with a creatinine clearance of $5 \mathrm{ml} / \mathrm{min}$, for 24 hours. Injections every eight $t \overrightarrow{\theta_{0}}$ 12 hours should therefore provide adequate bloo $\$$ levels in patients with chronic renal failure. Haemos dialysis leads to partial removal of cephalexin fronit the blood, but this study shows that an adequatos serum level is maintained during dialysis for up t $\dot{\theta}$ ? eight hours following intravenous administration of cephalexin IG. The mean half life of 5.6 hours in the three patients reported here is somewhat longer than the half life of between three and four hours reporteg by de Maine and Kirby (1971) in patients undergoing haemodialysis by the same technique.

We would like to thank Dr R. D. Foord, Glaxष Laboratories Ltd, for supplies of cephalexin and foo financial support.

\section{References}

Bennett, J. V., Brodie, J. L., Benner, E. J., and Kirby, W. M. M(1966). Simplified accurate method for antibiotic assay of clinical specimens. Appl. Microbiol., 14, 170-177.

de Maine, J. B., and Kirby, W. M. M. (1971). Clinical pharmacolog of cephalexin administered intravenously. Antimicrob. AgențS. Chemother., 10 (1970), 190-194.

Gower, P. E., and Dash, C. H. (1969). Cephalexin: Human studies a new cephalosporin antibiotic. Brit. J. Pharmacol., 37, 738-747.

Kabins, S. A., Kelner, B., Walton, E., and Goldstein, E. (1970श् Cephalexin therapy as related to renal function. Amer. J. med. Sci., 259, 133-142.

Kunin, C. M., and Finkelberg, Z. (1970). Oral cephalexin ane ampicillin: antimicrobial activity, recovery in urine and persistence in blood of uraemic patients. Ann. intern. Med 72, 349-356.

Kunin, C. M., and Finland, M. (1958). Demethylchlortetracycling New Engl. J. Med., 259, 999-1005.

Wick, W. E. (1967). Cephalexin, a new orally absorbed cephalosporin: antibiotic. Appl. Microbiol., 15, 765-769. 